CONTRAINDICATIONS: MICRONASE Tablets are contraindicated in patients with: 1. Known hypersensitivity or allergy to the drug. 2. Diabetic ketoacidosis, with or without coma. This condition should be treated with insulin. 3. Type I diabetes mellitus, as sole therapy.

SPECIAL WARNING ON INCREASED RISK OF CARDIOVASCULAR MORTALITY: The administration of oral hypoglycemic drugs has been reported to be associated with increased cardiovascular mortality as hypoglycemic drugs has been reported to be associated with increased cardiovascular mortality as compared to treatment with diet alone or diet plus insulin. This warning is based on the study conducted by the University Group Diabetes Program (UGDP), a long-term prospective clinical trial designed to
evaluate the effectiveness of glucose-lowering drugs in preventing or delaying vascular complications in patients with noninsulin-dependent diabetes. The study involved 823 patients who were randomly assigned to one of four treatment groups (Diabetes, 19 [Suppl 2]: 747-830, 1970).

UGDP reported that patients treated for 5 to 8 years with diet plus a fixed dose of tolbutamide (1.5 grams per day) had a rate of cardiovascular mortality approximately $21 / 2$ times that of patients treated with diet per day) had a rate of cardiovascular mortality approximately $2 \frac{1}{2}$ times that of patients treated with diet
alone. A significant increase in total mortality was not observed, but the use of tolbutamide was disconalone. A significant increase in total mortality was not observed, but the use of tolbutamide was discon-
tinued based on the increase in cardiovascular mortality, thus limiting the opportunity for the study to tinued based on the increase in cardiovascular mortality, thus limiting the opportunity for the study to the findings of the UGDP study provide an adequate basis for this warning. The patient should be informed of the potential risks and advantages of MICRONASE and of alternative modes of therapy.

Although only one drug in the sulfonylurea class (tolbutamide) was included in this study, it is prudent from a safety standpoint to consider that this warning may apply to other oral hypoglycemic drugs in this class, in view of their close similarities in mode of action and chemical structure.

PRECAUTIONS: General-Hypoglycemia: All sulfonylureas are capable of producing severe hypoglycemia. Proper patient selection and dosage and instructions are important to avoid hypoglycemic episodes. Rena or hepatic insufficiency may increase the risk of serious hypoglycemic reactions. Elderly, debilitated or malnourished patients, and those with adrenal or pituitary insufficiency, are particularly susceptible to the nourished patients, and the hypoglycemic action of glucose-lowering drugs. Hypoglycemia may be dificult to recognize in the elderly and in people who are taking beta-adrenergic blocking drugs. Hypoglycemia is more likely to occur when caloric intake is deficient, after severe or prolonged exercise, when alcohol is ingested, or when more than one glucose-lowering drug is used.

Loss of Control of Blood Glucose: In diabetic patients exposed to stress such as fever, trauma, infection or surgery, a loss of control may occur. It may then be necessary to discontinue MICRONASE and administer insulin Adequate adjusth

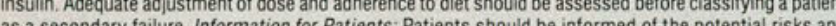
as a secondary failure. Information for Pationts: Patients should be informed of the potential risks an advantages of MICRONASE and of alternative modes of therapy. They also should be informed about the importance of adherence to dietary instructions, of a regular exercise program, and of regular testing of urine and/or blood glucose. The risks of hypoglycemia, its symptoms and treatment, and conditions that predispose to its development should be explained to patients and responsible family members. Primary and secondary failure should also be explained.

Laboratory Tests: Response to MICRONASE Tablets should be monitored by frequent urine glucose tests and periodic blood glucose tests. Measurement of glycosylated hemoglobin levels may be helpful in some patients. Drug Interactions: The hypoglycemic action of sulfonylureas may be potentiated by certain drugs including nonsteroidal anti-inflammatory agents and other drugs that are highly protein bound, salicylates, sulfonamides, chloramphenicol, probenecid, coumarins, monoamine oxidase inhibitors, and beta adrenergic blocking agents.

Certain drugs tend to produce hyperglycemia and may lead to loss of control. These drugs include the thiazides and other diuretics, corticosteroids, phenothiazines, thyroid products, estrogens, oral contraceptives. phenytoin, nicotinic acid, sympathomimetics, calcium channel blocking drugs, and isoniazid.

A potential interaction between oral miconazole and oral hypoglycemic agents leading to severe hypoglycemia has been reported.

Carcinogenesis, Mutagenesis, and Impairment of Fertility: Studies in rats at doses up to $300 \mathrm{mg} / \mathrm{kg} /$ day for 18 months showed no carcinogenic effects. Glyburide is nonmutagenic when studied in the Salmonella microsome test (Ames test) and in the DNA damage/alkaline elution assay.

Pregnancy: Teratogenic effects: Pregnancy Category B. Reproduction studies in rats and rabbits have revealed no evidence of impaired fertility or harm to the fetus due to glyburide. There are no adequate and well controlled studies in pregnant women. This drug should be used during pregnancy only if clearly needed. Insulin should be used during pregnancy to maintain blood glucose as close to normal as possible. Nonteratogenic Effects: Prolonged severe hypoglycemia ( 4 to 10 days) has been reported in neonates born to mothers who Effects: Prolonged severe hypoglycemia ( 4 to 10 days) has been reported in neonates born to mothers who
were receiving a sulfonylurea drug at the time of delivery. MICRONASE should be discontinued at least two were receiving a sulfonylurea drug at the
weeks before the expected delivery date.

Nursing Mothers: Some sulfonylurea drugs are known to be excreted in human milk. Insulin therapy should be considered.

Pediatric Use: Safety and effectiveness in children have not been established.

ADVERSE REACTIONS: Hypoglycemia: See Precautions and Overdosage sections. Gastrointestinal Reactions: Cholestatic jaundice and hepatitis may occur rarely: MICRONASE Tablets should be discontinued if this occurs. Gastrointestinal disturbances (nausea, epigastric fullness, and heartburn) occurred in $1.8 \%$ of patients during clinical trials. They were the most commonly reported adverse reactions. They tend to be dose related and may disappear when dosage is reduced. Liver function abnormalities have been reported Dermatologic Reactions: Allergic skin reactions, e. pruritus, erythema, urticaria, and morbilliform or maculopapular eruptions occurred in $1.5 \%$ of patients during trials. These may be transient and may disapmaculopapular eruptions occurred in $1.5 \%$ of patients during trials. These may be transient and may disappear despite continued use of MICRONASE; if skin reactions persist, the drug should be discontinued. Porphyria cutanea tarda and photosensitivity reactions have been reported with sulfonylureas. Hematologic Reactions: Leukopenia, agranulocytosis, thrombocytopenia, hemolytic anemia, aplastic anema, and pancytopenia have been reported with sulfonylureas. Melabolic Reactions. Hepalic porphyia and disulfiramlike reactions have been report MICRONASE and disulfiram-like reactions have been reported very rarely. Cases of hyponatremia have been reported with glyburide and all other sulfonylureas, most often in patients who are on other medications or have medical conditions known to cause hyponatremia or increase release of antidiuretic hormone. (SIADH) have medical conditions known to cause hyponatremia or increase release of antidiuretic hormone. (SIADH)
secretion has been reported with certain other sulfonylureas, and it has been suggested that these sulfonylureas may augment the peripheral (antidiuretic) action of ADH and/or increase release of ADH.

OVERDOSAGE: Overdosage of sulfonylureas, including MICRONASE Tablets, can produce hypoglycemia. If hypoglycemic coma is diagnosed or suspected, the patient should be given a rapid intravenous injection of thicose solution. This should be followr (10\%) glucose solution at a rate which will maintain the blood glucose at a level above $100 \mathrm{mg} / \mathrm{dL}$. Patients should be closely monitored for a minimum of 24 to 48 hours, since hypoglycemia may recur after apparent clinical recovery.

Maximum Dose: Daily doses of more than $20 \mathrm{mg}$ are not recommended

Dosage Interval: Once-a-day therapy is usually satisfactory. Some patients, particularly those receiving more than $10 \mathrm{mg}$ daily, may have a more satisfactory response with twice-a-day dosage

Specific Patient Populations: MICRONASE is not recommended for use in pregnancy or for use in children. In elderly patients, debilitated or malnourished patients, and patients with impaired renal or hepatic function, the initial and maintenance dosing should be conservative to avoid hypoglycemic reactions. (See Precautions Section).

For additional product information see your Upjohn representative.

\title{
Reviews
}

\section{Peripheral vascular surgery}

By Wade C. Lamberth, Jr., and Donald B. Doty. Pp 341, with illus. Year Book Medical Publishers, Inc, $35 \mathrm{E}$ Wacker Dr, Chicago, 60601, 1987, $\$ 77.00$.

Part of a surgical atlas series, this text presents peripheral vascular procedures used by the vascular or general surgeon in a concise step-bystep format. It is designed as a reference or review source for the surgical resident and the practicing surgeon. Peripheral vascular surgery compares favorably with the books, Operative techniques in vascular surgery, edited by John J. Bergan, MD, and James S.T. Yao, MD, PhD, and Atlas of vascular surgery, by Falls B. Hershey, MD, and Carl H. Calman, MD.

Lamberth and Doty's work features a wide range of procedures with concise discussions and clear illustrations. Unlike the earlier texts, Peripheral vascular surgery includes sections on basic technique, amputations, fasciotomies, sympathectomies, and in situ vein bypass. However, discussion of portal hypertension surgery and angiography were omitted as well as bibliographic references for each discussion. Including standard alternate anatomic approaches to the various peripheral vessels plus bibliographic references would prove helpful.

Producing a concise, complete surgical atlas for peripheral vascular surgery is a difficult achievement for any author. Nonetheless, I think $P e$ ripheral vascular surgery comes closest to being as complete an atlas as any book presently in print. This textbook represents a clear, current, and 


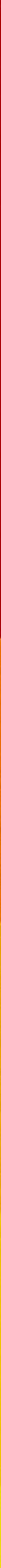




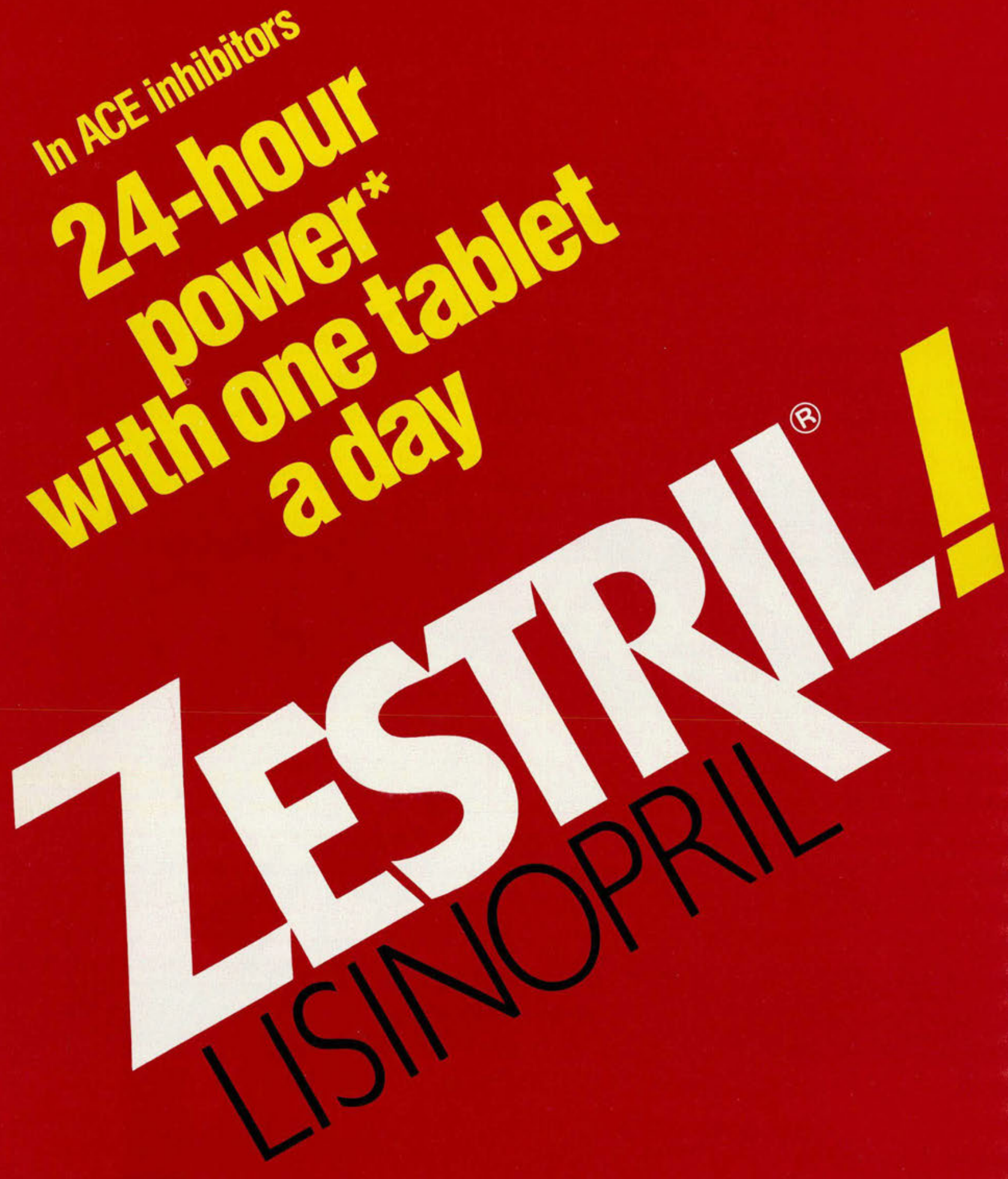

\section{Zestril: The long-acting ACE inhibitor}

Zestril achieves 24-hour blood pressure control with a half-life of 12 hours. Angiotensin converting enzyme (ACE) inhibition t is long lasting with Zestrilsustained 24 hours after a single dose. ${ }^{2 \cdot 4}$ 


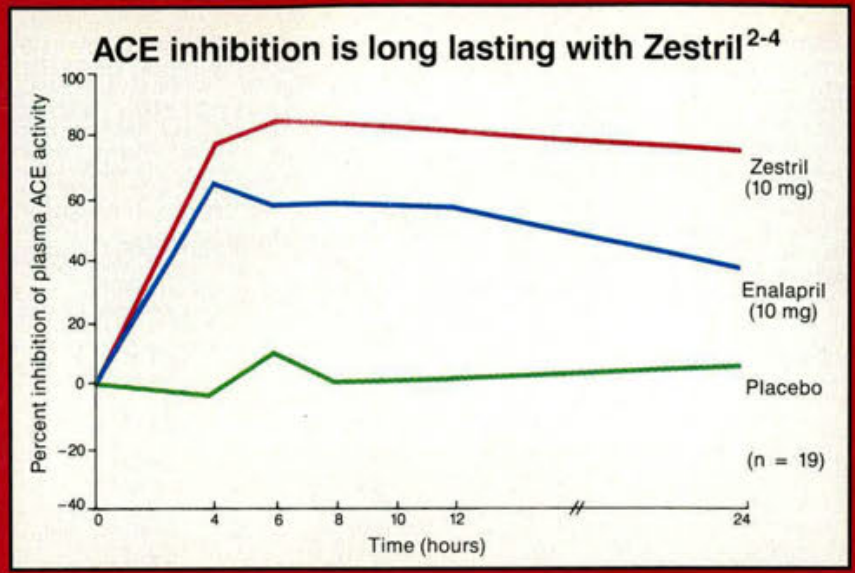

† In pharmacodynamic studies (utilizing $10 \mathrm{mg}$ of enalapril and lisinopril), ACE inhibition was significantly correlated to plasma renin activity and fall in diastolic blood pressure in normal volunteers. ${ }^{3}$

- adapted from Ajayi et al, p $424^{2}$

The clinical significance of pharmacodynamic differences among ACE inhibitors observed in normal volunteers has not been determined in hypertensive patients.

\section{Zestril: Hypertensive patients start and stay at one tablet a day}

A single tablet of Zestril reduces blood pressure for 24 hours ${ }^{1}-$ unlike other ACE inhibitors, which may have to be increased to b.i.d. ${ }^{5}$ or t.i.d. ${ }^{6}$ dosing in some patients. The predictable once-daily dosage of Zestril enhances patient compliance and cost-effectiveness.

\section{Zestril: 24-hour blood pressure control that's easy to live with}

Zestril shares the low incidence of side effects characteristic of ACE inhibitors. Additionally, rash or taste disturbance is rarely seen with Zestril. What's more, Zestril is not metabolized by the liver. It is absorbed as the active drug and does not require bioactivation ${ }^{7}$-as needed with prodrugs such as enalapril. ${ }^{\ddagger 5}$ Absorption of Zestril is unaffected by food. ${ }^{8}$

- Evaluation of the hypertensive patient should always include assessment of renal function. (See Dosage and Administration.)

- Angioedema has been reported with ACE inhibitors, including Zestril. (See Warnings.)

(C) 1988 ICI Americas Inc.

* The antihypertensive effect may diminish at the end of the dosing interval.

¥Clinical significance has not been determined in hypertensive patients. 


\section{ZESTRIL ${ }^{*}$ (lisinopril)}

INDICATIONS AND USAGE. Zestril is indicated for the treatment of hypertension. It may be used alone as initial therapy or concomitantly with other classes of antihypertensive agents. In using Zestril, consideration should be given to the fact that another angiotensin converting enzyme inhibitor, captopril, has caused
agranulocytosis, particularly in patients with renal impairment or collagen vascular disease, and that available data are insufficient to show that Zestril does not have a similar risk. (See WARNINGS.) CONTTRAINDICATIONS. Zestril is contraindicated in patients who are hypersensitive to this product. WARNINGS. Angioedema: Angioedema of the face, extremities, lips, tongue, glottis and/or larynx has been reported in patients treated with angiotensin converting enzyme inhibitors, including Zestril. In such cases, Zestril should be promptly discontinued, and the patient carefully observed until the swelling disappears. In instances where swelling
has been confined to the face and lips the condition has generally resolved without treatment, although antihistamines have been useful in relieving symptoms. Angioedema associated with laryngeal edema may be fatal. Where there is involvement of the tongue, glottis or larynx, likely to cause airway obstruction,
appropriate therapy, eg, subcutaneous epinephrine solution $1: 1000(0.3 \mathrm{~mL}$ to $0.5 \mathrm{~mL})$ should be promptly administered. (See ADVERSE REACTIONS.) Hypotension: Excessive hypotension was rarely seen in uncomplicated hypertensive patients but is a possible consequence of use with Zestril in salt/volume-depleted persons,
such as those treated vigorously with diuretics or patients on dialysis. (See PRECAUTIONS, Drug Interactions and ADVERSE REACTIONS.) In patients with severe congestive heart failure, with or without associated renal insufficiency, excessive hypotension has been observed and may be associated with oliguria and/or progressive these patients, therapy should be started under very close medical supervision. Such patients should be followed closely for the first two weeks of treatment and whenever the dose of Zestril and/or diuretic is increased. Similar considerations apply to patients with ischemic heart or cerebrovascular disease in whom an excessive fall in blood pressure could result in a myocardial infarction or cerebrovascular accident. If hypotension occurs, the patient should be placed in supine position and, if necessary, receive an intravenous infusion of normal saline. A transient hypotensive response is not a contraindication to further doses which usually can be given without difficulty once the blood pressure has increased after volume expansion. Neutropenia/Agranulocytosis: Another angiotensin converting enzyme inhibitor, captopril, has been shown to cause agranulocytosis and
bone marrow depression, rarely in uncomplicated patients but more frequently in patients with renal impairment especially if they also have a collagen vascular disease. Available data from clinical trials of Zestril are insufficient to show that Zestril does not cause agranulocytosis at similar rates. Periodic monitoring of white blood cell General. Impaired Renal Function: As a consequence of inhibiting the renin-angiotensin-aldosterone system, changes in renal function may be anticipated in susceptible individuals, In patients with severe congestive heart failure whose renal function may depend on the activity of the renin-angiotensin-aldosterone system,
treatment with angiotensin converting enzyme inhibitors, including Zestril, may be associated with oliguria treatment with angiotensin converting enzyme inhibitors, including Zestril, may be associated with oliguria unilateral or bilateral renal artery stenosis, increases in blood urea nitrogen and serum creatinine may occur. Experience with another angiotensin converting enzyme inhibitor suggests that these increases are usually reversible upon discontinuation of Zestril and/or diuretic therapy. In such patients, renal function should be
monitored during the first few weeks of therapy. Some hypertensive patients with no apparent pre-existing renal vascular disease have developed increases in blood urea nitrogen and serum creatinine, usually minor and transient, especially when Zestril has been given concomitantly with a diuretic. This is more likely to the diuretic may be required. Evaluation of the hypertensive patient should always include assessment of renal function. (See DOSAGE AND ADMINISTRATION.) Hyperkalemia: In clinical trials hyperkalemia (serum
potassium greater than $5.7 \mathrm{mEq} / \mathrm{L}$ ) occurred in approximately $2.2 \%$ of hypertensive patients and $4.0 \%$ of potassium greater than $5.7 \mathrm{mEq} / \mathrm{L}$ ) occurred in approximately $2.2 \%$ of hypertensive patients and $4.0 \%$ of
patients with congestive heart failure. In most cases these were isolated values which resolved despite continued therapy. Hyperkalemia was a cause of discontinuation of therapy in approximately $0.1 \%$ of hypertensive patients. Risk factors for the development of hyperkalemia include renal insufficiency, diabetes mellitus, and the concomitant use of potassium-sparing diuretics, potassium supplements and/or potassium-containing salt
substitutes, which should be used cautiously, if at all, with Zestril. (See Drug Interactions.) Surgery/Anesthesia: In patients undergoing major surgery or during anesthesia with agents that produce hypotension, Zestril may block angiotensin II formation secondary to compensatory renin release. If hypotension occurs and is con-
sidered to be due to this mechanism, it can be corrected by volume expansion. Information for Patients. Angioedema: Angioedema, including laryngeal edema, may occur especially following the first dose of Zestril. Patients should be so advised and told to report immediately any signs or symptoms suggesting angioedema (swelling of face, extremities, eyes, lips, tongue, difficulty in swallowing or breathing) and to take no more
drug until they have consulted with the prescribing physician. Symptomatic Hypotension: Patients should be cautioned to report lightheadedness especially during the first few days of therapy. If actual syncope occurs, the patient should be told to discontinue the drug until they have consulted with the prescribing physician. All patients should be cautioned that excessive perspiration and dehydration may lead to an excessive fall in blood pressure because of reduction in fluid volume. Other causes of volume depletion such as vomiting
or diarrhea may also lead to a fall in blood pressure; patients should be advised to consult with their physician. Hyperkalemia: Patients should be told not to use salt substitutes containing potassium without consulting their physician. Neutropenia: Patients should be told to report promptly any indication of infection (eg. sore throat, fever) which may be a sign of neutropenia. NOTE: As with many other drugs, certain advice to patients
being treated with Zestril is warranted. This information is intended to aid in the safe and effective use of being treated with Zestril is warranted. This information is intended to aid in the safe and effective use of this medication. It is not a disclosure of all possible adverse or intended effects. Drug Interactions. Hypo-
tension- Patients on Diuretic Therapy: Patients on diuretics and especially those in whom diuretic therapy was recently instituted, may occasionally experience an excessive reduction of blood pressure after initiation of therapy with Zestril. The possibility of hypotensive effects with Zestril can be minimized by either discontinuing the diuretic or increasing the salt intake prior to initiation of treatment with Zestril. If it is necessary to continue initial dose for at least two hours and until blood pressure has stabilized for at least an additional hour. (See WARNINGS, and DOSAGE AND ADMINISTRATION.) When a diuretic is added to the therapy of a patient receiving
Zestril, an additional antihypertensive effect is usually observed. Studies with ACE inhibitors in combination with diuretics indicate that the dose of the ACE inhibitor can be reduced when it is given with a diuretic. (See DOSAGE AND ADMINISTRATION.) Indomethacin: In a study in 36 patients with mild to moderate hypertension where the antihypertensive effects of Zestril alone were compared to Zestril given concomitantly with indomethacin, the use of indomethacin was associated with a reduced effect, although the difference between the two regimens was not significant. Other Agents: Zestril has been used concomitantly with nitrates and/or digoxin without evidence of clinically significant adverse interactions. No clinically important pharmacokinetic interactions occurred when Zestril was used concomitantly with propranolol or hydrochlorothiazide. The
presence of food in the stomach does not alter the bioavailability of Zestril. Agents Increasing Serum Potassium: Zestril attenuates potassium loss caused by thiazide-type diuretics. Use of Zestril with potassium-sparing diuretics (eg, spironolactone, triamterene or amiloride), potassium supplements, or potassium-containing salt substitutes may lead to significant increases in serum potassium. Therefore, if concomitant use of these monitoring of serum potassium. Carcinogenesis, Mutagenesis, Impairment of Fertility. There was no evidence of a tumorigenic effect when lisinopril was administered for 105 weeks to male and female rats at doses up to $90 \mathrm{mg} / \mathrm{kg} / \mathrm{day}$ (about 56 times* the maximum recommended daily human dose) or when lisinopril was administered for 92 weeks to (male and female) mice at doses up to $135 \mathrm{mg} / \mathrm{kg} / \mathrm{day}$ (about 84 times* the in the Ames microbial mulily human dose). "Based on patient weight of $50 \mathrm{Kg}$. Lisinopri was not mutagenic mutation assay using Chinese hamster lung cells. Lisinopril did not produce single strand DNA breaks in an in vitro alkaline elution rat hepatocyte assay. In addition, lisinopril did not produce increases in chromosomal There were an in vitro test in Chinese hamster ovary cells or in an in vivo study in mouse bone marrow. $300 \mathrm{mg} / \mathrm{kg} / \mathrm{day}$ of lisinopril. Pregnancy. Pregnancy Category C: Lisinopril was not teratogenic in mice treated on days 6-15 of gestation with up to $1,000 \mathrm{mg} / \mathrm{kg} / \mathrm{day}$ (625 times the maximum recommended human dose). There was an increase in fetal resorptions at doses down to $100 \mathrm{mg} / \mathrm{kg}$; at doses of $1,000 \mathrm{mg} / \mathrm{kg}$ this was prevented by saline supplementation. There was no fetotoxicity or teratogenicity in rats treated with up to
$300 \mathrm{mg} / \mathrm{kg} / \mathrm{day}$ ( 188 times the maximum recommended dose) of lisinopril at days 6-17 of gestation. In rats receiving lisinopril from day 15 of gestation through day 21 postpartum, there was an increased incidence increase in pup deaths and decrease in pup weight did not occur with maternal saline supplementation Lisinopril, at doses up to $1 \mathrm{mg} / \mathrm{kg} / \mathrm{day}$, was not teratogenic when given throughout the organogenic period in saline supplemented rabbits. Saline supplementation (physiologic saline in place of tap water) was usede dosage level. The rabbit has been shown to be extremely sensitive to angiotensin converting enzyme inhibitors (captopril and enalapril) with maternal and fetotoxic effects apparent at or below the recommended therapeutic at a dose of lisinopril at $1 \mathrm{mg} / \mathrm{kg} / \mathrm{day}$ and by an increased incidence of incomplete ossification at the lowes dose tested $(0.1 \mathrm{mg} / \mathrm{kg} / \mathrm{day})$ ). By whole body autoradiography, radioactivity was found in the placenta following administration of labeled lisinopril to pregnant rats, but none was found in the fetuses. There are no adequate
and well-controlled studies in pregnant women. Zestril should be used during pregnancy only if the potentia benefit justifies the potential risk to the fetus. Nursing Mothers: Milk of lactating rats contains radioactivity
ZESTRIL* (lisinopril)

Because many drugs are excreted in human milk, caution should be exercised when Zestril is given to a nursing Zestril has been found to be generally well tolerated in controlled clinical trials involving 2003 patients and subjects. The most frequent clinical adverse experiences in controlled trials were dizziness $(6.3 \%)$, headach
$(5.3 \%)$, fatique $(3.3 \%)$, diarrhea $(3.2 \%)$, upper respiratory symptoms $(30 \%)$, and cough $(2.9 \%)$, all of which were more eqe (3.3) , un in transient in nature. Discontinuation of therapy was required in $6.0 \%$ of patients. In clinical trials, the overal frequency of adverse experiences could not be related to total daily dosage within the recommended therapeutic dosage range. For adverse experiences which occurred in more than $1 \%$ of patients and subjects treated with Zestril or Zestril plus hydrochlorothiazide in controlled clinical trials,
listed in the table below. Percent of Patients in Controlled Studies

\begin{tabular}{|lccc|}
\hline & $\begin{array}{c}\text { Zestril } \\
\text { (n }=2003 \dagger) \\
\text { Incidence } \\
\text { (discontinuation) }\end{array}$ & $\begin{array}{c}\text { Zestril/Hydrochlorothiazide } \\
\left(\begin{array}{l}n=644) \\
\text { Incidence } \\
\text { (discontinuation) }\end{array}\right.\end{array}$ & $\begin{array}{c}\text { Placebo } \\
(\mathrm{n}=207 \text { ) } \\
\text { Incidence }\end{array}$ \\
\hline Dizziness & $6.3(0.6)$ & $9.0(0.9)$ & 1.9 \\
Headache & $5.3(0.2)$ & $4.3(0.5)$ & 1.9 \\
Fatigue & $3.3(0.2)$ & $3.9(0.5)$ & 1.0 \\
Diarrhea & $3.2(0.3)$ & $2.6(0.3)$ & 2.4 \\
Upper Respiratory Symptoms & $3.0(0.0)$ & $4.5(0.0)$ & 0.0 \\
Cough & $2.9(0.4)$ & $4.5(0.8)$ & 1.0 \\
Nausea & $2.3(0.3)$ & $2.5(0.2)$ & 2.4 \\
Hypotension & $1.8(0.8)$ & $1.6(0.5)$ & 0.5 \\
Rash & $1.5(0.4)$ & $1.6(0.2)$ & 0.5 \\
Orthostatic Effects & $1.4(0.0)$ & $3.4(0.2)$ & 1.0 \\
Asthenia & $1.3(0.4)$ & $2.0(0.2)$ & 1.0 \\
Chest Pain & $1.3(0.1)$ & $1.2(0.2)$ & 1.4 \\
Vomiting & $1.3(0.2)$ & $1.4(0.0)$ & 0.5 \\
Dyspnea & $1.1(0.0)$ & $0.5(0.2)$ & 1.4 \\
Dyspepsia & $1.0(0.0)$ & $1.9(0.0)$ & 0.0 \\
Paresthesia & $0.8(0.0)$ & $2.0(0.2)$ & 0.0 \\
Impotence & $0.7(0.2)$ & $1.6(0.3)$ & 0.0 \\
Muscle Cramps & $0.6(0.0)$ & $2.8(0.6)$ & 0.5 \\
Back Pain & $0.5(0.0)$ & $1.1(0.0)$ & 1.4 \\
Nasal Congestion & $0.3(0.0)$ & $1.2(0.0)$ & 0.0 \\
Decreased Libido & $0.2(0.1)$ & $1.2(0.0)$ & 0.0 \\
Vertigo & $0.1(0.0)$ & $1.1(0.2)$ & 0.0 \\
\hline
\end{tabular}

fincludes 420 patient

Clinical adverse experiences occurring in $03 \%$ to $1.0 \%$ of patients in the controlled trials and rarer serious possibly drug related events reported in uncontrolled studies or marketing experience included: BODY AS rhythm disturbances, tachycardia, peripheral edema, palpitation. DIGESTIVE: Abdominal pain, anorexia, conrimythm disturbances, tachycardia, peripheral edema, palpitation. DIGESTIVE: Abdominal pain, anorexia, con TEM/PSYCHIATRIC: Depression, somnolence, insomnia, stroke. RESPIRATORY SYSTEM: Bronchitis, sinusitis, pharyngeal pain. UROGENITAL: Oliguria, progressive azotemia, acute renal failure. OTHER: Blurred vision pruritus, urinary tract infection, vasculitis of the legs. ANGIOEDEMA: Angioedema has been reported in patients
receiving Zestril ( $0.1 \%)$. Angioedema associated with laryngeal edema may be fatal. If angioedema of the face, extremities, lips, tongue, glottis and/or larynx occurs, treatment with Zestril should be discontinued face, extremities, lips, tongue, glottis and/or larynx occurs, treatment with Zestril should be discontinued
and appropriate therapy instituted immediately. (See WARNINGS.) HYPOTENSION: In hypertensive patients, hypotension occurred in $1.2 \%$ and syncope occurred in $0.1 \%$ of patients. Hypotension or syncope was a
cause of discontinuation of therapy in $0.5 \%$ of hypertensive patients. (See WARNINGS.) In patients with canse of dive heart failure, hypotension occurred in $5.0 \%$ and syncope occurred in $1.0 \%$ of p patients. These
adverse experiences were causes for discontinuation of therapy in $1.3 \%$ of these patients. Clinical Laboratory Test Findings. Serum Electrolytes: Hyperkalemia (See PRECAUTIONS.) Creatinine, Blood Urea Nitrogen: Minor increases in blood urea nitrogen and serum creatinine, reversible upon discontinuation of therapy, were observed in about $2.0 \%$ of patients with essential hypertension treated with Zestril alone. Increases were
more common in patients receiving concomitant diuretics and in patients with renal artery stenosis. (S PRECAUTIONS.) Reversible minor increases in blood urea nitrogen and serum creatinine were observed in approximately $9.1 \%$ of patients with congestive heart failure on concomitant diuretic therapy. Frequently,
these abnormalities resolved when the dosage of the diuretic was decreased. Hemoglobin and Hematocrit: Small decreases in hemoglobin and hematocrit (mean decreases of approximately $0.4 \mathrm{~g} \%$ and $1.3 \mathrm{vol} \%$, Small decreases in hemoglobin and hematocrit (mean decreases of approximately $0.4 \mathrm{~g} \%$ and $1.3 \mathrm{vol} \%$,
respectively) occurred frequently in patients treated with Zestril but were rarely of clinical importance in patients without some other cause of anemia. In clinical trials, less than $0.1 \%$ of patients discontinued therapy due to anemia. Other (Causal Relationship Unknown): Rarely, elevations of liver enzymes and/or serum bilirubin elevations in blood urea nitrogen $(0.6 \%)$, serum creatinine $(0.5 \%)$, and serum potassium $(0.4 \%)$. OVERDOSAGE. dosage would be hypotension, for which the usual treatment would be intravenous infusion of normal saline solution. DOSAGE AND ADMINISTRATION. Initial Therapy: In patients with uncomplicated essential hypertension not on diuretic therapy, the recommended initial dose is $10 \mathrm{mg}$ once a day. Dosage should be adjuste according to blood pressure response. The usual dosage range is $20-40 \mathrm{mg}$ per day administered in a sing
daily dose. The antihypertensive effect may diminish toward the end of the dosing interval regardless of the administered dose, but most commonly with a dose of $10 \mathrm{mg}$ daily. This can be evaluated by measuring blood it is not, an increase in dose should be considered. Doses up to $80 \mathrm{mg}$ have been used but do not appea to give greater effect. If blood pressure is not controlled with Zestril alone, a low dose of a diuretic may be diuretic, it may be possible to reduce the dose of Zestril. Diuretic Treated Patients: In hypertensive patients Who are currently being treated with a diuretic, symptomatic hypotension may occur occasionally following therapy with Zestril to reduce the likelihood of hypotension. (See WARNINGS.) The dosage of Zestril shou be adjusted according to blood pressure response. il the patients blood pressure is notcontrolled wi h Zes dose of $5 \mathrm{mg}$ should be used under medical supervision for at least two hours and until blood pressure has dose of $5 \mathrm{mg}$ should be used under medical supervision for at least two hours and until blood pressure has
stabilized for at least an additional hour. (See WARNIINGS and PRECAUTIONS. Drug Interactions.) Concomitart administration of Zestril with potassium supplements, potassium salt substitutes, or potassium-sparin
diuretics may lead to increases of serum potassium. (See PRECAUTIONS.) Use in Elderly: In general, bloo pressure response and adverse experiences were similar in younger and older patients given similar dos concentration time curve (AUC) are doubled in older patients so that dosage adjustments should be made
with particular caution. Dosage Adjustment in Renal Impairment: The usual dose of Zestril (10 mg) recommended for patients with creatinine clearance $>30 \mathrm{~mL} / \mathrm{min}$ (serum creatinine of up to approximately $3 \mathrm{mg} / \mathrm{dL}$ ). For patients with creatinine clearance $>10 \mathrm{~mL} / \mathrm{min} \leq 30 \mathrm{~mL} / \mathrm{min}$ (serum creatinine $\geq 3 \mathrm{mg} / \mathrm{dL}$ ). $3 \mathrm{mg} / \mathrm{dL}$ ). For patients with creatinine clearance $>10 \mathrm{~mL} / \mathrm{min} \leq 30 \mathrm{~mL} / \mathrm{min}$ (serum creatinine $\geq 3 \mathrm{mg} / \mathrm{dL}$ )
the first dose is $5 \mathrm{mg}$ once daily. For patients with creatinine clearance $<10 \mathrm{~mL} / \mathrm{min}$ (usually on hemodialysis
the recommended initial dose is $2.5 \mathrm{mg}$. The dosage may be titrated upward until blood pressure is controlled the recommended initial dose is $25 \mathrm{~m}$
or to a maximum of $40 \mathrm{mg}$ daily.

\begin{tabular}{|lcc|}
\hline Renal Status & Creatinine-Clearance $\mathrm{mL} / \mathrm{min}$ & Initial Dose mg/cay \\
\hline Normal Renal Function to Mild Impairment & $>30$ & 10 \\
Moderate to Severe Impairment & $\geq 10 \leq 30$ & 5
\end{tabular}

Dialysis Patients

FDosage or dosing interval should be adjusted depending on the blood press
Stuart Pharmaceuticals, Division of ICI Americas Inc., Wilmington, DE 19897.

REFERENCES: 1. Zestrilo (lisinopril) full prescribing information issued May 1988. 2. Aiayi AA, Campbell BC Res 1985;5(6): 419-427. 3. Millar JA, Derlox FHM, McLean K, et al: Pharmacodynamics of converting enzyme inhibition: The cardiovascular, endocrine and autonomic effects of MKA21 (enalapril) and MK521. Br J Cin Pharmacol 1982, 14:347-35
4. Hodsman GP. Zabludowski JR. Zoccali C, et al: Enalapril (MK421) and its lysine analogue (MK521): A compariso of acute and chronic effects on blood pressure, renin-angiotensin system and sodium excretion in normal man. Br JC

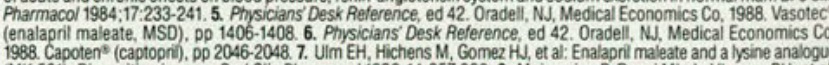
1988. Capoten" (captoprí), pp 2046-2048. 7. Ulm EH, Hichens M, Gomez HV, et al: Enalapril maleate and a lysine analogu
(MK-521): Disposition in man. Br J Clin Pharmacol 1982; 14:357-362. 8. Mojaverian P. Rocci ML Jc. Vlasses PH, et a
Effect of food on the bioavailability of lisinopril, a nonsulfhydryl angiotensin-converting enzyme inhibitor. J Pharm SC 
manageable vascular surgery atlas. It would be a useful addition to any resident's or surgeor's library.

CRAIG McBRAYER, DO

Assistant Professor of Surgery

Chicago College of Osteopathic

Medicine

Chicago, Ill

\section{Logan Turner's Diseases of the nose, throat and ear}

Edited by A.G.D. Maran. Ed 10. Pp 456, with illus. PSG Publishing $\mathrm{Co}$, Inc, 545 Great Rd, PO Box 6, Littleton, MA 01460, $1988, \$ 29.50$ (paper).

Divided into four sections-- the nose; head and neck; the ear; and and pediatrics-this book covers otolaryngology concisely.

The areas comprised here, such as salivary gland tumors, deal with surgical anatomy along with various medical and surgical conditions involving the salivary glands. Types of tumors concerning these structures are discussed as well as postsurgical complications.

Of particular interest, the chapter on pediatric otolaryngology nicely covers the primary concerns of tonsils and adenoids; laryngeal stridor; intubation and tracheostomy; congenital defects of the larynx (subglottic stenosis); head and neck tumors; hearing problems; and acute ear and mastoid infections.

Although DeWeese and Saunder's Textbook of otolaryngology is the preferred text for residents, the book in question presents a good general overview. It would benefit the medical student on an ear, nose and throat rotation, first year otolaryngology residents, and serve as a general reference for the general practitioner.

\section{JOHN ALTER, DO}

Pontiac, Mich

\section{Computed cranial \& spinal imaging: A practical introduction}

By John M. Stevens, Alan R. Valentine, and Brian E. Kendall. Pp 248, with illus. Williams \& Wilkins, 428 E Preston St, Baltimore, 21202, 1988, $\$ 44.95$.

Computed axial tomography (CT) and magnetic resonance imaging (MRI) are modalities readily available in the United States and routinely used in medicine. The fundamentals of these imaging applications, while basic to radiology, are often overlooked in a primary care curriculum. This book attempts to provide these basics in an introductory text. The first chapters deal with the physical principles of these modalities. While brief, these initial chapters adequately hit the highlights.

Those pages devoted to anatomy, especially its functional aspects, are much too involved and inappropriate for an introductory text. Furthermore, this subject seems out of place in a book dedicated to imaging. Many discussed structures are distinctly beyond the resolving power of these imaging modalities. Several line drawings included here do not directly correlate to MR or CT images, which markedly detracts from their usefulness.

The remaining sections encompass disease entities by presenting brief descriptions and representative images, primarily CT studies. Generally these images are of average quality; however, some serve as suboptimal examples. In particular, one dealing with multiple sclerosis was mislabeled and upside down.

Overall Computed cranial \& spinal imaging: A practical introduction attempts to provide the nonradiologist in training with some basics of CT and MRI of the brain and spine. In that context it does so adequately. Nonetheless, I would not recommend it to anyone with more than a passing interest in these two very important imaging modalities concerning the central nervous system.

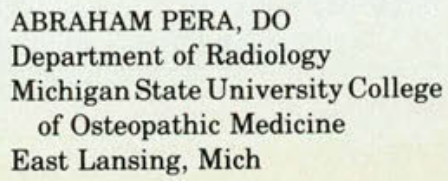

Books received

\section{Anatomy}

Oxford textbook of functional anatomy: Thorax and abdomen, Vol 2. By Pamela C.B. MacKinnon and John F. Morris; pp 138, with illus; Oxford University Press, 200 Madison Ave, New York, 10016, 1988 , $\$ 24.95$ (paper).

\section{Immunology}

Immunology essentials of surgical practice. Edited by Luis H. Toledo-Pereyra; pp 421, with illus; PSG Publishing Co, Inc, 545 Great Rd, PO Box 6, Littleton, MA $01460,1988, \$ 69.50$.

\section{Of general interest}

The reverse effect: How vitamins and minerals promote health and cause disease. By Walter A. Heiby; pp 1198, with illus; MediScience Publishers, PO Box 256, Deerfield, IL $60015,1988, \$ 59.50$.

\section{Orthopedics}

Foot function: A programmed text. By Michael O. Seibel; pp 264, with illus; Williams \& Wilkins, 428 East Preston St, Baltimore, 21202, 1988, $\$ 39.50$ (paper).

\section{Osteopathic manipulative treatment}

Manual medicine therapy. By Werner Schneider, Jiři Dvořák, and Thomas Tritschler. Translated and edited by Wolfgang G. Gilliar, DO, and Philip E. Greenman, DO; pp 148, with illus; Thieme Medical Publishers, Inc, 381 Park Ave South, New York, 10016, 1988, $\$ 59.00$.

\section{Practice management}

Acquiring and enhancing physicians practices: Strategic issues and implementation guidelines for hospitals and physicians. By Steven Portnoy, Ross E. Stromberg, and Philip A. Newbold; pp 146, with illus; American Hospital Publishing, Inc, 211 East Chicago Ave, Chicago, 60611, $1988, \$ 35.00$ (paper) $\$ 28.00$ AHA members.

Fundamentals of private practice in physical therapy. By Mark A. Brimer; pp 224, with illus; Charles C Thomas•Publishers, 2600 South First St, Springfield, IL 62794$9265, \$ 29.75$.

\section{Sports medicine}

The 'E' factor: The secrets of new tech training and fitness for the winning edge. By Bob Goldman, DO, and Ronald Klatz, DO; pp 575, with illus; William Morrow \& Co, Inc, 105 Madison Ave, New York, $10016,1988, \$ 24.95$. 